stage against the physiological races mentioned above, the results were most satisfactory (see table). The system of recording the reaction is that adopted by Stackman and Levine ${ }^{3}$.

This is a most striking result, since the reaction of its two parents under the same conditions, both in the greenhouse as seedlings and as adult plants in the field rust nursery, is definitely towards the susceptible scale.

Note. The formula of $B_{1} S_{3}$ is suggested here as a substitute for the existing system applied especially by the American geneticists, who would give the family the formula $B C_{1} F_{3}$. I suggest that $F$ should only be restricted to families resulting from pure selfing as originally used by Mendel, and used ever since. $S$ for selfing can be used in such cases where selfing started after an initial backcross, as in the case reported here. $B$ is substituted for $B C$ for backcross, since it seems much simpler. I am putting this suggestion before those concerned.

\section{Ahmed Afifi}

Royal Agricultural Society, Cairo.

1 El-Hilaly, A. F., Phytopath., 38 (1948).

Philp, J., and Selim, A. G., Nature, 147 (1941).

3 Minn. Agric. Exp. Stat., Tech. Bull., 8 (1922).

\section{In vitro Inhibition of Bacterium tularense by Methylene Blue}

Ir has been found that very low concentrations $(0.5 \mu \mathrm{gm} . / \mathrm{ml}$.) of methylene blue inhibit the growth in vitro of Bact. tularense. This inhibition is of the same order of magnitude as that caused by the most potent antibiotics ${ }^{1}$. The dye had, however, no effect in vivo; doses of $0.5 \mathrm{gm}$. each, applied intraperitoneally for three successive days, did not protect mice infected even with low doses $\left(1-10 L D_{b_{0}}\right)$ of the bacterium.

For the in vitro experiments, the organism was grown on a glucose-cysteine-blood-agar medium; the slopes were inoculated with a standard loop-full of a thick bacterial suspension. Three highly virulent strains and three of low virulence were used; the latter were derived from the former by means described in another communication ${ }^{2}$.

As a rule, basic dyes of the methylene blue type are much more active against Gram-positive than against Gram-negative bacteria ${ }^{3}$. Thus Diplococcus pneumonice Type I is inhibited by $5 \mu \mathrm{gm} . / \mathrm{ml}$., Staphylococcus aureus and Streptococcus pyogenes by $10 \mu \mathrm{gm}$., and Streptococcus foccalis by $20 \mu \mathrm{gm}$. of the dye, whereas Shigella dysenteria requires a dose of $200 \mu \mathrm{gm} . / \mathrm{ml} .{ }^{4}$.

Although the position of Bact. tularense in the system of bacteria is not clear, some authors ${ }^{5,6}$ classify the organism with the Pasteurella or Brucella group. A number of representatives of these two groups were, therefore, tested for their response to methylene blue with the same technique as Bact.tularense. Two strains of Brucella melitensis, Brucella abortus, and Brucella suis were completely inhibited by $5 \mu \mathrm{gm} . / \mathrm{ml}$. of the dye. On the other hand, two strains of Pasteurella pestis required $1,000 \mu \mathrm{gm} . / \mathrm{ml}$. of methylene blue for complete inhibition, and Pasteurella pseudotuberculosis and Pasteurella septica grew even at this concentration of the dye, though rather poorly.
Recent investigations have led to the view that low concentrations of methylene blue specifically interfere with metabolic reactions other than oxidation or fermentation processes?. If this theory be correct, it is likely that biochemically Bact. tularense resembles the Brucella group of bacteria.

\section{H. YanIV}

J. Avi-Dor

Microbiological Laboratories,

Weizmann Institute of Science, Rehovoth.

Aug. 29.

1 Eigelsbach, H. F., and Herring, R. D., Abstracts Soc, Amer. Bacteriologists, 49th Meeting, 67 (1949).

${ }^{2}$ Avi-Dor, J., and Yaniv, H. (to ke published).

s Dubos, R. J., Ann. Rev. Biochem., 11, 659 (1942).

${ }^{4}$ Petroff, S. A., and Gumn, W. S., J. Lab. Clin. Med., 20, 689 (1985). "Topley and Wilson's "Principles of Pacteriology and Immunity",

- Zinsser's "Textbook of Bacteriology", 521 (ninth edit., 1948).

'Stokes, J. L., Bacteriological Proceedings, 119 (1950).

\section{Two Types of Inhibition of the Hydrogen- Oxygen Reaction by Hydrocarbons}

THE inhibiting effect of hydrocarbons on the hydrogen - oxygen reaction was discovered during the course of a war-time study, described elsewhere ${ }^{1}$, of the problem of exhaust flames from aero-engines. Preliminary experiments at that time showed that this inhibiting effect was obtained with a range of hydrocarbons from pentane to octane, as well as with the lower alcohols.

Recently, this inhibition has been studied in more detail by examining the effect of the simpler hydrocarbons on the second limit of hydrogen-oxygen mixtures in clean and potassium chloride-coated 'Pyrex' vessels. With propane, as with the higher hydrocarbons studied earlier, an almost linear relation between explosion pressure and inhibitor concentration is obtained, so that the effectiveness of the inhibitor may be conveniently defined by $i_{1 / 2}$ (the concentration required to reduce the limit by 50 per cent). A study of the effect of mixture composition, vessel diameter and vessel surface, shows that, to a first approximation, $i_{1 / 2}$ is directly proportional to the oxygen concentration, independent of the hydrogen concentration, independent of the diameter of the vessel, and is not substantially affected by change from a clean 'Pyrex' to a potassium chloride-coated vessel.

The dependence on oxygen concentration is most simply interpreted as a competition between the reaction of a centre with oxygen giving propagation or branching, and a reaction with propane which ultimately leads to termination. Since the only centres reacting with oxygen in the hydrogen - oxygen reaction are hydrogen atoms, the primary inhibition reaction appears to be uniquely defined. Addition of the reaction,

$$
\mathrm{H}+\mathrm{C}_{3} \mathrm{H}_{8} \stackrel{k_{7}}{=} \mathrm{C}_{3} \mathrm{H}_{7}+\mathrm{H}_{2},
$$

to the accepted mechannism ${ }^{2}$ for the second limit gives the relation:

$$
c\left(P_{0}-P\right)=k_{7} i / k_{\mathbf{6}} y,
$$

where $i, y$ are the mole fractions of propane and oxygen, and $c$ is a constant determined by the third- 